\title{
Optical Coherence Tomography Angiography for Macular Telangiectasia Type 2
}

\author{
Sunny Chi Lik Au ${ }^{1 *}$, Clarice Kai-ying $\mathrm{Su}^{2}$ \\ ${ }^{1}$ Department of Ophthalmology, Tung Wah Eastern Hospital, Hong Kong \\ ${ }^{2}$ La Ka Shing Faculty of Medicine, The University of Hong Kong, Hong Kong \\ *Corresponding Author: Sunny Chi Lik Au, Department of Ophthalmology, Tung Wah Eastern Hospital, \\ Hong Kong; Email: kilihcua@gmail.com \\ Received Date: 01-01-2022; Accepted Date: 02-02-2022; Published Date: 09-02-2022 \\ Copyright $^{\odot} 2022$ by Au SCL, et al. All rights reserved. This is an open access article distributed under the terms \\ of the Creative Commons Attribution License, which permits unrestricted use, distribution and reproduction in \\ any medium, provided the original author and source are credited.
}

\begin{abstract}
Optical Coherence Tomography Angiography (OCT-A) is an evolving retinal imaging modality for vascular diseases. By avoiding the intravenous fluorescein dye and its associated complications, OCT-A better identifies abnormal vasculature in the retinal and choroidal layers without any interference from fluorescein leakage. This is particularly useful for visualization of pathology in macular telangiectasia. Classified as non-proliferative and proliferative, macular telangiectasia can eventually progress to subretinal neovascularization. In this article, we review its pathology at different stages and corresponding OCT-A findings in different retinal layers: from the superficial and deep retinal capillary plexus, through the retinal pigment epithelium, and down to the choriocapillaris layers.
\end{abstract}

\section{Keywords}

Optical Coherence Tomography Angiography; Macular Telangiectasia; Retina; Choroid; Imaging 


\section{Introduction}

\section{Optical Coherence Tomography Angiography}

With the advancement of technology in speed and resolution, retinal imaging is not limited to optical coherence tomography or Fluorescein Angiography (FA) alone [1]. New imaging modality that uses motion contrast to provide a non-invasive image of the retinal and choroidal vasculature is called Optical Coherence Tomography Angiography (OCTA) [2]. The principle behind is sequential B-scan images over same retinal location, with subsequent analysis of change in amplitude and phase, inferred as flow of red blood cells in vasculature [3]. This cube scan generates a 3-dimensional image set and its extension provides en-face view of the vasculature at different layers of the retina [4]. Therefore, a flow-based imaging is available on top of the intensity-based B-scan imaging [5].

Spectral Domain (SD) and Swept Source (SS) OCTA are 2 major systems of imaging for commercially available OCTA machines [6,7]. SD OCTA utilizes $840 \mathrm{~nm}$ light source with a bandwidth of $50-90 \mathrm{~nm}$ for imaging [8]. The A-scan rate is of 68,000 - 70,000 scans per seconds, whereas the axial resolution, transverse resolution and A-scan depth are variable among different brands of OCTA machines, but much finer than traditional optical coherence tomography [7,9]. In contrast, SS OCTA uses 1,050 nm light source with A-scan rate of 100,000 scans per second [10]. With the longer wavelength over the invisible infrared spectrum, advantage of SS OCTA is not only limited to more comfortable patient experience during the scan, but also better tissue penetration for better image quality of the choroid $[11,12]$. Besides, the faster scan speed allows more scans over the same position, thus better suppression of motion artifacts, allowing wider field imaging with greater resolution.

Most commercially available OCTA machines process the function of autosegmentation, which split the 3-dimensional images into "slabs", to reflect a known anatomic layer of the retinal vasculature [13]. Inner, middle, outer retinal and choriocapillaris slabs are pre-set tissue slabs commonly applied clinically for imaging respectively the Superficial Capillary Plexus (SCP), deep Capillary Vascular Plexus (DCP), outer retina to Retinal Pigment Epithelium (RPE) layer and choriocapillaris layers [14]. Border of computer segmented reference planes are listed in Table 1 and manual adjustment of predefined slabs boundaries are possible to facilitate visualisation on pathology of interest [15].

Other than eliminating the risk of nausea and anaphylaxis from exogenous intravenous dye injection [16,17]. OCTA imaging allows visualization of the true anatomy over the pathological vasculature, without blockage from the leaking fluorescein [18]. This advantage is especially useful in studying vascular pathology involving different layers such as agerelated macular degeneration, diabetic macular edema, macular telangiectasia etc. [19]. We will focus on the discussion on macular telangiectasia type 2 in this article. 


\begin{tabular}{|c|c|c|c|}
\hline & Slab & Corresponding retinal layers & Boundary \\
\hline 1 & $\begin{array}{c}\text { Superficial } \\
\text { retinal slab }\end{array}$ & $\begin{array}{c}\text { Superficial retinal capillary } \\
\text { plexus }\end{array}$ & $\begin{array}{c}3 \mu \mathrm{m} \text { below the internal limiting membrane } \\
\text { to } 15 \mu \mathrm{m} \text { below the inner plexiform layer }\end{array}$ \\
\hline 2 & $\begin{array}{c}\text { Deep retinal } \\
\text { slab }\end{array}$ & $\begin{array}{c}\text { Deep retinal capillary plexus } \\
15 \mu \mathrm{m} \text { below the inner plexiform layer to } \\
70 \mu \mathrm{m} \text { below the inner plexiform layer }\end{array}$ \\
\hline 3 & $\begin{array}{c}\text { Outer retinal } \\
\text { slab }\end{array}$ & $\begin{array}{c}\text { Outer retina to Retinal Pigment } \\
\text { Epithelium (RPE) } \\
\text { (no vasculature normally) }\end{array}$ & $\begin{array}{c}70 \mu \mathrm{m} \text { below the inner plexiform layer to } \\
30 \mu \mathrm{m} \text { below the RPE }\end{array}$ \\
& $\begin{array}{c}\text { Choriocapillaris } \\
\text { Choroid }\end{array}$ & $\begin{array}{c}30 \mu \mathrm{m} \text { below the RPE reference to } 60 \mu \mathrm{m} \\
\text { below the RPE reference }\end{array}$ \\
\hline
\end{tabular}

Table 1: Commonly used slabs in Optical Coherence Tomography Angiography.

\section{Macular Telangiectasia Type 2}

First coined by Gass in 1968, classified in system by Gass and Oyakawa in 1982, later modified by Gass and Blodi in 1993, macular telangiectasia is also known as idiopathic juxtafoveal retinal telangiectasia or parafoveal telangiectasia [20-22]. With a prevalence of $0.1 \%$, subject to under diagnosis from its minimal visual symptoms in early stages, this rare disease is thought to be a neurodegenerative disease, originating from Muller cell dysfunction and death causing vascular insult, leading to irreversible loss of inner and outer retinal tissue and photoreceptors, progressing towards macular atrophy [23-27]. At present, widely adopted classification is by Yannuzzi in 2006, based on clinical observation, FA, indocyanine green angiography and spectral domain optical coherence tomography, into idiopathic macular telangiectasia (MacTel) type 1 (aneurysmal telangiectasia) and type 2 (perifoveal telangiectasia) [28,29]. (Table 2) MacTel 2 is further divided into non-proliferative (telangiectasia and foveal atrophy) and proliferative (subretinal neovascular, SRNV) stage.

Starting from the temporal aspect of parafoveal DCP, MacTel 2 later extends circumferentially around fovea with dilated anastomoses between SCP and DCP, invading the Outer Nuclear Layer (ONL) with inner segment/ outer segment/ ellipsoid zone (IS/OS/EZ) loss. The slightly dilated and blunted retinal vessels over temporal parafoveal retina appear to form right angles and travel towards the outer retina [30]. With disease progression, Subretinal Neovascularization (SRNV) originate from both the deep retinal and choroidal circulations [31]. This process which involves all microvascular layers of retina makes it ideal for OCTA imaging.

Patients are asymptomatic or with non-specific complaint of blurring of vision at early stages of disease, [24] but with disease progression, metamorphopsia, paracentral or central scotoma will be symptomatic to affect daily living [32,33]. Clinically, Mac Tel 2 is seen bilaterally, but asymmetrically, as loss of retinal transparency with a grayish coloration over temporal juxtafoveolar area initially with time parafoveal capillary telangiectasia appears mainly on temporal side of macula, progressing to multiple tiny intraretinal golden refractile crystalline deposits near the telangiectasia and stellate foci of intraretinal pigment clumping along the

Au SCL | Volume 3; Issue 1 (2022) | JOAR-3(1)-028 | Short Communication

Citation: Au SCL, et al. Optical Coherence Tomography Angiography for Macular Telangiectasia Type

2. J Ophthalmol Adv Res. 2022;3(1):1-10.

DOI: http://dx.doi.org/10.46889/JOAR.2022.3101 
right-angled vessels, later cystic cavities or even SRNV membrane, with or without haemorrhages, become obvious on fundus examination.[27,34-38]. With a mean age in $5^{\text {th }}$ to $6^{\text {th }}$ decades of life, MacTel 2 has a slight female gender predilection and a high association with hypertension and diabetes [23,38-43].

\begin{tabular}{|c|c|c|}
\hline Classifications & Gass & Yannuzzi \\
\hline Type & 1A & 1 \\
\hline & 1B & 1 \\
\hline & 2A & 2 \\
\hline & 2B & Deleted \\
\hline & 3A & Deleted \\
\hline & 3B & Deleted \\
\hline
\end{tabular}

Table 2: Classification of Macular Telangiectasia type 2.

\section{OCTA Imaging of MacTel 2}

On the OCTA cross-sectional B-scan, intraretinal hyporeflective spaces are within the inner retina, usually located in the foveal pit, with a predilection for the temporal slope. This inner lamella cyst over the foveolar appears as tissue lost, with the Internal Limiting Membrane (ILM) spanning across or draping over it [24,44]. This ILM drape is characteristically not associated with increased retinal thickening, as if diabetic macula edema or retinal vein occlusion [45]. With disease progression, the inner retinal layers collapse over the cavity and appose onto the RPE. In contrast, hyperreflective intraretinal or inner retinal lesions usually represent the pigment plaques, whereas macula thickening caused by intra- and/or sub-retinal fluid signifies secondary SRNV over the outer neurosensory retinal layers.

En-face OCTA images identify abnormal microvasculature in perifoveal region, especially the temporal DCP of retina. Foveal Avascular Zone (FAZ) appears to be dragged temporally towards the emergency venule. First OCTA images of MacTel 2 was published by Thorell and others in 2014 with the use of SS OCTA using the Optical Coherence Tomography Microangiography (OMAG) algorithm with a scan pattern of $3 \times 3 \mathrm{~mm}$ area centered on the fovea [46]. The OMAG algorithm scans a total of $300 \mathrm{~B}$-scan separated $10 \mu \mathrm{m}$ apart over a 3 $\mathrm{mm}$ distance, with roughly $3.8 \mathrm{~ms}$ between consecutive scan, to image the microvascular network. Later, few other groups published OCTA images of MacTel 2 with SD OCTA $[47,48,49]$. With better understanding of the disease with OCTA, a system of grading for MacTel is even available based on OCTA findings [50]. 


\section{Non-proliferative MacTel 2}

In early stage 1 , there is only deep retinal capillary telangiectasia. En-face OCTA images usually demonstrate mildly dilated vessels in retinal DCP (Deep Retinal Slab) from the middle retinal layer predominantly over temporal side of fovea; without alternation in microvasculature in superficial layers, i.e. no abnormal blood flow in the superficial retinal slab (Fig. 1). Capillary density remains normal for both SCP and DCP (Fig. 2). Microcysts other than the large cystic cavities are sometimes observed over the ganglion cell and inner nuclear layers, which correspond those small lacunae in the SCP and DCP [31].

In intermediate stage 2, vascular changes involve both the SCP and DCP, inner retinal capillary telangiectasia sets in. En-face OCTA images show multiple, telangiectatic, microaneurysmallike dilated vessels residing within the middle retinal layer, extending to inner and outer retina (superficial and deep retinal slabs). One or more sets of dilated draining venules originate at right-angle from temporal part macular telangiectatic vascular net may be observed adjacent to the inner foveal cystic spaces [51]. There is loss of vascular density in both SCP and DCP from capillary dropout, with widening of intervascular spaces, but outer retinal slab is absent from abnormal flow signal [52].

In stage 3, telangiectatic vascular invasion involves the full thickness of the retina. Variable sizes of pigment clumps, if present, will pose an optical shadowing effect. There is greater capillary dropout over SCP and DCP and wider intervascular spaces compared to stage 2. FAZ is dragged temporally towards emergence of the dilated venules, becoming distorted and irregular in shape. However, the FAZ size is variable, depending on the presence of subinternal limiting membrane vascular ingrowth into FAZ or capillary dropout, which give a larger or smaller FAZ respectively. There may also be additional layers of newly formed capillaries invading the avascular ONL, causing IS/OS/EZ disruption [53]. 


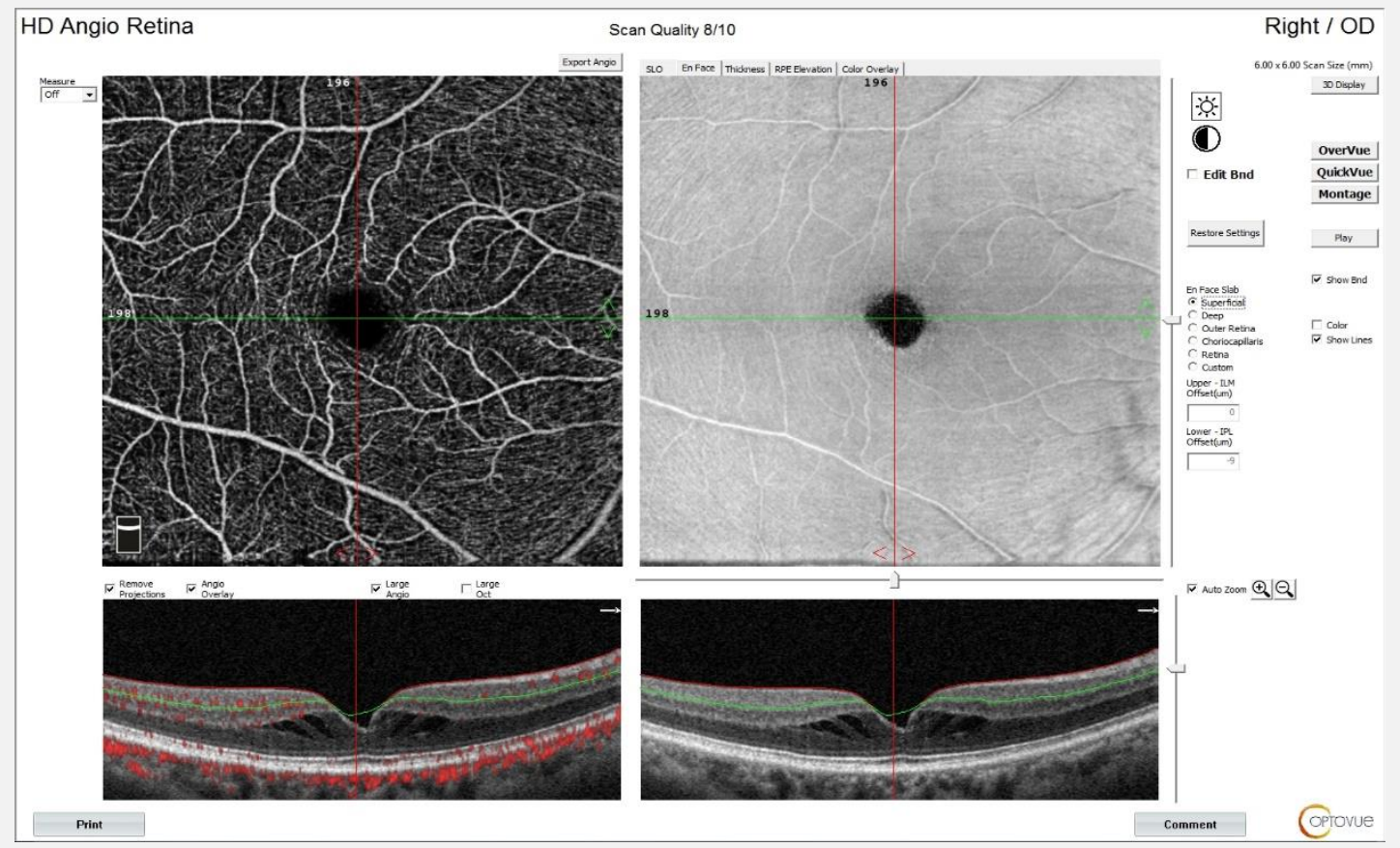

Figure 1: The images of the superficial retinal capillary plexus in optical coherence tomography angiography of a Stage 1 Macular Telangiectasia type 2 eye.

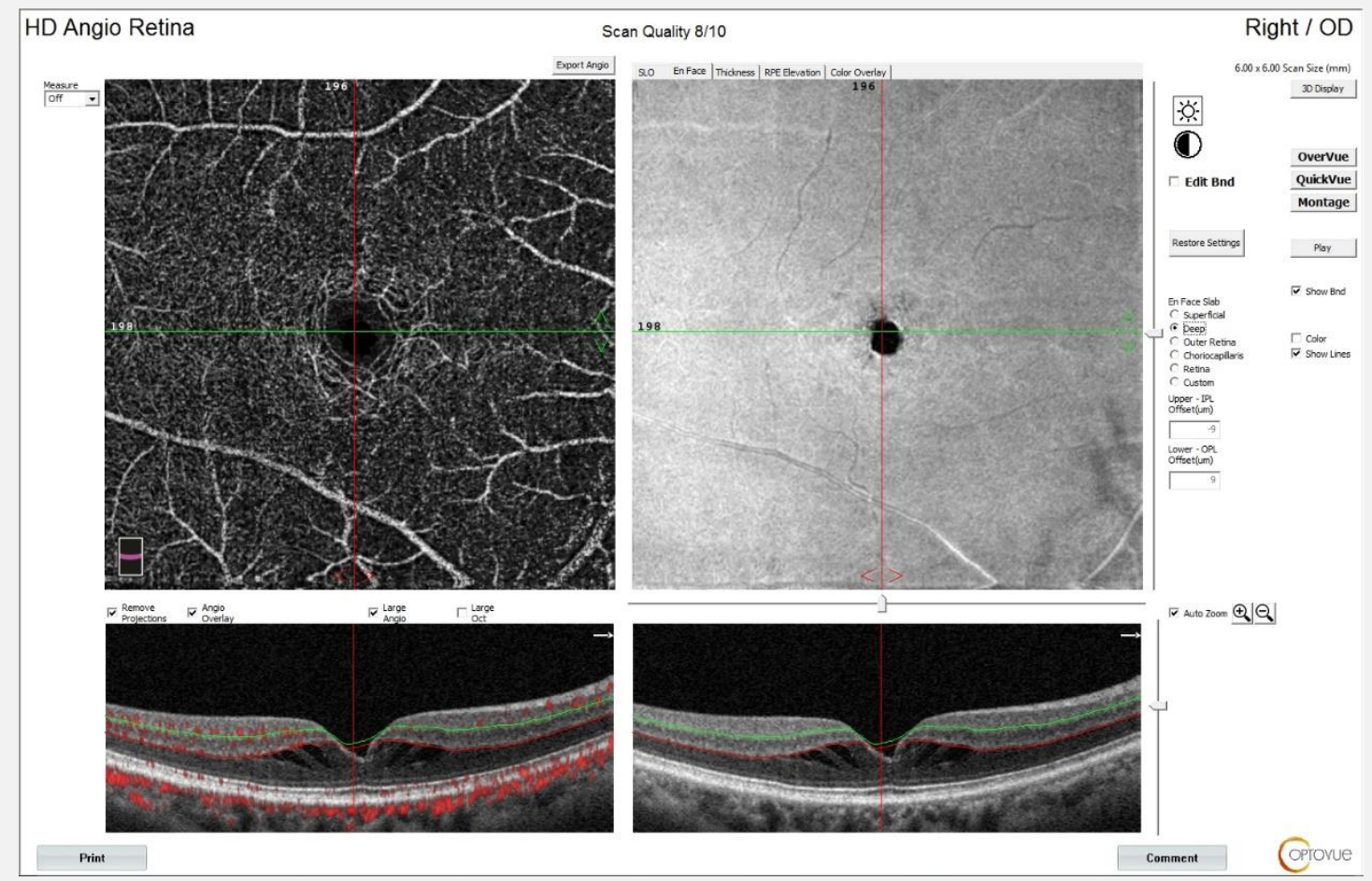

Figure 2: The images of the deep retinal capillary plexus in optical coherence tomography angiography of a Stage 1 Macular Telangiectasia type 2 eye.

Au SCL | Volume 3; Issue 1 (2022) | JOAR-3(1)-028 | Short Communication

Citation: Au SCL, et al. Optical Coherence Tomography Angiography for Macular Telangiectasia Type

2. J Ophthalmol Adv Res. 2022;3(1):1-10.

DOI: http://dx.doi.org/10.46889/JOAR.2022.3101 


\section{Proliferative MacTel 2}

In stage 4 disease, SRNV develops with significant pigment clumping. Flow signal blockage by pigment clumping is typical. OCTA en-face images show alternation in juxtafoveal capillary network, with prominent anastomoses extending to outer retina, disrupting the IS/OS/EZ. There is significant capillary dropout, with severe distortion of vascular flow pattern. As SRNV communicates to both retinal and choroidal circulations, blood flow of an SRNV can be detected in the outer retinal slab, or even the choroid capillary slab [54]. Meanwhile, OCTA Bscan demonstrated neurosensory retina elevation, with or without retinal edema, by the SRNV and subretinal fibrovascular pigmented plaque. Hyperreflectivity on OCTA B-scan arises from intraretinal pigment and subretinal haemorrhage may be appreciated.

Although routine anti-Vascular Endothelial Growth Factor (VEGF) is not recommended, efficacy of anti-VEGF in proliferative Mac Tel 2 has been reported and effective in controlling the SRNV to protect patients from severe visual loss [55-61]. With anti-VEGF treatment, OCTA demonstrated decrease in calibers of retinal vessels and their anastomoses [31]. It is also observed that microaneurysms with the telangiectasia vessels disappeared on OCTA, yet whether the lesion is regressed or the blood flow within is diminished to undetectable remains a question.

\section{Late Atrophic Stage}

In stage 5, fibrovascular proliferation and subretinal fibrosis develops. OCTA en-face images show significantly distorted and stretched macular vessels, with reduction in vascular volume and capillary dropout on superficial and deep retinal slabs. On the contrary, blood flow from the disciform fibrovascular membrane is well seen on outer retinal and choroid capillary slabs. FAZ is distorted, dragged and enlarged. Eventually, the macula appears abnormally thin from enlargement of intraretinal cysts with collapse of empty spaces. Telangiectasia persists, with a decrease in capillary density.

\section{Conclusion}

OCTA has the advantages of non-invasive and repeatable imaging for disease diagnosis and disease progression or treatment response monitoring. It is also a faster and cheaper imaging modality that provides good 3-diemnsional image quality on microvasculature of retina and choroid, not obscured by fluorescein leakage.

\section{Conflict of Interest}

The authors declare no conflict of interest, financial or otherwise. 


\section{References}

1. Arya M, Rashad R, Sorour O, Moult EM, Fujimoto JG, Waheed NK. Optical Coherence Tomography Angiography (OCTA) flow speed mapping technology for retinal diseases. Expert Rev Med Devices. 2018;15(12):875-82.

2. Kashani AH, Chen CL, Gahm JK, Zheng F, Richter GM, Rosenfeld PJ, et al. Optical coherence tomography angiography: A comprehensive review of current methods and clinical applications. Prog Retin Eye Res. 2017;60:66-100.

3. Chen CL, Wang RK. Optical coherence tomography based angiography. Biomed Opt Express. 2017;8(2):1056-82.

4. Zang P, Liu G, Zhang M, Wang J, Hwang TS, Wilson DJ, et al. Automated three-dimensional registration and volume rebuilding for wide-field angiographic and structural optical coherence tomography. J Biomed Opt. 2017;22(2):26001.

5. Hagag AM, Gao SS, Jia Y, Huang D. Optical coherence tomography angiography: Technical principles and clinical applications in ophthalmology. Taiwan J Ophthalmol. 2017;7(3):115-29.

6. Liu G, Jia Y, Pechauer AD, Chandwani R, Huang D. Split-spectrum phase-gradient optical coherence tomography angiography. Biomed Opt Express. 2016;7(8):2943-54.

7. Li XX, Wu W, Zhou H, Deng JJ, Zhao MY, Qian TW, et al. A quantitative comparison of five optical coherence tomography angiography systems in clinical performance. Int J Ophthalmol. 2018;11(11):178495.

8. Wang F, Zhang Q, Deegan AJ, Chang J, Wang RK. Comparing imaging capabilities of spectral domain and swept source optical coherence tomography angiography in healthy subjects and central serous retinopathy. Eye Vis (Lond). 2018;5:19.

9. Hirano T, Chanwimol K, Weichsel J, Tepelus T, Sadda S. distinct retinal capillary plexuses in normal eyes as observed in optical coherence tomography angiography axial profile analysis. Sci Rep. 2018;8(1):9380.

10. Lavinsky F, Lavinsky D. Novel perspectives on swept-source optical coherence tomography. Int J Retina Vitreous. 2016;2:25.

11. Diaz JD, Wang JC, Oellers P, Lains I, Sobrin L, Husain D, et al. Imaging the deep choroidal vasculature using spectral domain and swept source optical coherence tomography angiography. J Vitreoretin Dis. 2018;2(3):146-54.

12. Lane M, Moult EM, Novais EA, Louzada RN, Cole ED, Lee B, et al. Visualizing the choriocapillaris under drusen: comparing 1050-nm swept-source versus 840-nm spectral-domain optical coherence tomography angiography. Invest Ophthalmol Vis Sci. 2016;57(9):585-90.

13. Rommel F, Siegfried F, Kurz M, Brinkmann MP, Rothe M, Rudolf M, et al. Impact of correct anatomical slab segmentation on foveal avascular zone measurements by optical coherence tomography angiography in healthy adults. J Curr Ophthalmol. 2018;30(2):156-60.

14. Khadamy J, Abri Aghdam K, Falavarjani KG. An update on optical coherence tomography angiography in diabetic retinopathy. J Ophthalmic Vis Res. 2018;13(4):487-97.

15. Yokoyama T, Maruko I, Koizumi H, Ishikawa Y, Iida T. Unmeasurable small size of foveal avascular zone without visual impairment in optical coherence tomography angiography. Eye (Lond). 2018;32(6):1062-6.

16. Kwiterovich KA, Maguire MG, Murphy RP, Schachat AP, Bressler NM, Bressler SB, et al. Frequency of adverse systemic reactions after fluorescein angiography: results of a prospective study. Ophthalmol. 1991;98:1139-42.

17. Yannuzzi LA, Rohrer KT, Tindel LJ, Sobel RS, Costanza MA, Shields W, et al. Fluorescein angiography complication survey. Ophthalmol. 1986;93:611-7.

18. Tan ACS, Tan GS, Denniston AK, Keane PA, Ang M, Milea D, et al. An overview of the clinical applications of optical coherence tomography angiography. Eye (Lond). 2018;32(2):262-86.

19. Villegas VM, Kovach JL. Optical coherence tomography angiography of macular telangiectasia type 2 with associated subretinal neovascular membrane. Case Rep Ophthalmol Med. 2017;2017:8186134.

Au SCL | Volume 3; Issue 1 (2022) | JOAR-3(1)-028 | Short Communication 
20. Gass JD. A fluorescein angiographic study of macular dysfunction secondary to retinal vascular disease: V retinal telangiectasis. Arch Ophthalmol. 1968;80(5):592-605.

21. Gass JD, Oyakawa RT. Idiopathic juxtafoveal retinal telangiectasis. Arch Ophthalmol. 1982;100(5):769-80.

22. Gass JD, Blodi BA. Idiopathic juxtafoveal telangiectasis. Update of classification and follow-up study. Ophthalmol. 1993;100(1):1536-46.

23. Klein R, Blodi B, Klein B. The prevalence of Macular Telangiectasia Type 2 (MT2) in the Beaver Dam eye study. Am J Ophthalmol. 2010;150(1):55-62.

24. Nowilaty SR, Al-Shamsi H, Al-Khars W. Idiopathic juxtafoveolar retinal telangiectasis: a current review. Middle East Afr J Ophthalmol. 2010;17(3):224-41.

25. Zhao M, Andrieu-Soler C, Kowalczuk L, Cortés MP, Berdugo M, Dernigoghossian M, et al. A new CRB1 rat mutation links Muller glial cells to retinal telangiectasia. J Neurosci. 2015;35(15):6093-106.

26. Powner M, Gillies M, Zhu M, Vevis K, Hunyor A, Fruttinger M. Loss of Muller's cells and photoreceptors in macular telangiectasia Type 2. Ophthalmol. 2013;120(11):2344-52.

27. Charbel Issa P, Gillies MC, Chew EY. Macular telangiectasia type 2. Prog Retin Eye Res. 2013;34:49-77.

28. Yannuzzi LA, Bardal AM, Freund KB, Chen KJ, Eandi CM, Blodi B. Idiopathic macular telangiectasia. Arch Ophthalmol. 2006;124(4):450-60.

29. Chew E, Gillies M, Bird A. Macular telangiectasia: a simplified classification. Arch Ophthalmol. 2006;124(4):573-4.

30. Nalcı H, Şermet F, Demirel S, Özmert E. Optical coherence tomography angiography findings in type-2 macular telangiectasia [published correction appears in Turk J Ophthalmol. 2018;48(1):56]. Turk J Ophthalmol. 2017;47(5):279-84.

31. Zhang Q, Wang R, Chen C, Legarreta AD, Durbin MK, An L, et al. Swept source optical coherence tomography angiography of neovascular macular telangiectasia type 2. Retina. 2015;35(11):2285-99.

32. Charbel Issa P, Holz FG, Scholl HP. Metamorphopsia in patients with macular telangiectasia type 2. Doc Ophthalmol. 2009;119:133-40.

33. Vujosevic S, Heeren TFC, Florea D, Leung I, Pauleikhoff D, Sallo F, et al. Scotoma characteristics in macular telangiectasia type 2: MacTel Project Report No. 7-The MacTel Research Group. Retina. 2018;38(1):S14-9.

34. Khodabande A, Roohipoor R, Zamani J. Management of Idiopathic Macular Telangiectasia Type 2. Ophthalmol Ther. 2019;8(2):155-75.

35. Sallo FB, Leung I, Chung M, Wolf-Schnurrbusch UE, Dubra A, Williams DR, et al. Retinal crystals in type 2 idiopathic macular telangiectasia. Ophthalmology. 2011;118(12):2461-7.

36. Leung I, Sallo FB, Bonelli R, Clemons TE, Pauleikhoff D, Chew EY, et al. Characteristics of pigmented lesions in type 2 idiopathic macular telangiectasia. Retina. 2018;38 (1):S43-50.

37. Au A, Hou K, Baumal CR, Sarraf D. Radial hemorrhage in Henle layer in macular telangiectasia type 2. JAMA Ophthalmol. 2018;136(10):1182-5.

38. Kim SH, Oh J, Ahn SE, Park CY, Oh JH. Demographic features of idiopathic macular telangiectasia in Korean patients. Korean J Ophthalmol. 2015;29(3):155-9.

39. Wu L, Evans T, Arevalo JF. Idiopathic macular telangiectasia type 2 (idiopathic juxtafoveolar retinal telangiectasis type 2A, Mac Tel 2). Surv Ophthalmol. 2013;58(6):536-9.

40. Ronquillo CC, Wegner K, Calvo CM, Bernstein PS. genetic penetrance of macular telangiectasia type 2. JAMA Ophthalmol. 2018;136(10):1158-63.

41. Elias A, Gopalakrishnan M, Anantharaman G. Risk factors in patients with macular telangiectasia $2 \mathrm{~A}$ in an Asian population: A case-control study. Indian J Ophthalmol. 2017;65(9):830-4.

42. Jhingan M, Marsonia K, Shukla D, Rosenfeld PJ, Chhablani J. Idiopathic macular telangiectasis type 2 and co-existent diabetic retinopathy. Int J Retina Vitreous. 2017;3:50.

43. Clemons TE, Gillies M, Chew EY, Bird AC, Peto T. Baseline characteristics of participants in the natural history study of macular telangiectasia (MacTel) MacTel project report no. 2. Ophthalmic Epidemiol. 2010;17:66-73.

44. Paunescu LA, Ko TH, Duker JS, han A, Drexler W, Schuman JS, et al. Idiopathic juxtafoveal retinal telangiectasis: new findings by ultrahigh-resolution optical coherence tomography. Ophthalmol. 2006;113(1):48-57.

Au SCL | Volume 3; Issue 1 (2022) | JOAR-3(1)-028 | Short Communication

Citation: Au SCL, et al. Optical Coherence Tomography Angiography for Macular Telangiectasia Type

2. J Ophthalmol Adv Res. 2022;3(1):1-10.

DOI: http://dx.doi.org/10.46889/JOAR.2022.3101 
45. Wu L. When is macular edema not macular edema? An update on macular telangiectasia type 2. Taiwan J Ophthalmol. 2015;5(4):149-55.

46. Thorell MR, Zhang Q, Huang Y, An L, Durbin MK, Laron M, et al. Sweptsource OCT angiography of macular telangiectasia type 2. Ophthalmic Surg Lasers Imaging Retina. 2014; 45: 369-80.

47. Zeimer M, Gutfleisch M, Heimes B, Spital G, Lommatzsch A, Pauleikhoff D. Association between changes in macular vasculature in optical coherence tomography- and fluorescein- angiography and distribution of macular pigment in type 2 idiopathic macular telangiectasia. Retina. 2015;35:2307-16.

48. Spaide RF, Klancnik JM Jr, Cooney MJ. Retinal vascular layers in macular telangiectasia type 2 imaged by optical coherence tomographic angiography. JAMA Ophthalmol. 2015;133:66-73.

49. Spaide RF, Klancnik JM Jr, Cooney MJ, Yannuzzi LA, Balaratnasingam C, Dansingani KK, et al. Volumerendering optical coherence tomography angiography of macular telangiectasia type 2. Ophthalmology. 2015;122:2261-9.

50. Toto L, Di Antonio L, Mastropasqua R, Mattei PA, Carpineto P, Borrelli E, et al. Multimodal imaging of macular telangiectasia type 2 : focus on vascular changes using optical coherence tomography angiography. Invest Ophthalmol Vis Sci. 2016;57(9):268-76.

51. Tzaridis S, Heeren T, Mai C, Thiele S, Holz FG, Issa PC, et al. Right-angled vessels in macular telangiectasia type 2. Br J Ophthalmol. 2021;105(9):1289-96.

52. Chidambara L, Gadde SG, Yadav NK, Jayadev C, Bhanushali D, Appaji AM, et al. Characteristics and quantification of vascular changes in macular telangiectasia type 2 on optical coherence tomography angiography. Br J Ophthalmol. 2016;100:1482-8.

53. Gaudric A, Krivosic V, Tadayoni R. Outer retina capillary invasion and ellipsoid zone loss in macular telangiectasia type 2 imaged by optical coherence tomography angiography. Retina. 2015;35:2300-6.

54. Micevych PS, Lee HE, Fawzi AA. Overlap between telangiectasia and photoreceptor loss increases with progression of macular telangiectasia type 2. PLoS One. 2019;14(10):e0224393.

55. Charbel Issa P, Finger R, Kruse K, Baumuller S, Scholl HP, Holz FG. Monthly ranibizumab for nonproliferative macular telangiectasia Type 2: a 12-month prospective study. Am J Ophthalmol. 2011;151(5):876-86.

56. Sigler EJ, Randolph JC, Catzada JI, Charles S. Comparison of observation, intravitreal bevacizumab, or pars plana vitrectomy for non-proliferative Type 2 macular telangiectasia. Graefes Arch Clin Exp Ophthalmol. 2013;251(4):1097-101.

57. Roller AB, Folk JC, Patel NM, Boldt HC, Russell SR, Abramoff MD, et al. Intravitreal bevacizumab for treatment of proliferative and nonproliferative type 2 idiopathic macular telangiectasia. Retina (Philadelphia, Pa). 2011;31(9):1848-55.

58. Karagiannis D, Georgalas I, Ladas I, Eustratios P, Mitropoulos P. A case of subretinal neovascularization treated with intravitreal ranibizumab in a patient with idiopathic juxtafoveal retinal telangiectasis. Clin Interv Aging. 2009;4:63-5.

59. Mandal S, Venkatesh P, Abbas Z, Vohra R, Garg S. Intravitreal bevacizumab (Avastin) for subretinal neovascularization secondary to type 2A idiopathic juxtafoveal telangiectasia. Graefes Arch Clin Exp Ophthalmol. 2007;245:1825-9.

60. Narayanan R, Chhablani J, Sinha M, Dave V, Tyagi M, Pappuru RR, et al. Efficacy of anti-vascular endothelial growth factor therapy in subretinal neovascularization secondary to macular telangiectasia type 2. Retina (Philadelphia, PA). 2012;32(10):2001-5.

61. Chatziralli IP, Sharma PK, Sivaprasad S. Treatment modalities for idiopathic macular telangiectasia: an evidence-based systematic review of the literature. Semin Ophthalmol. 2017;32(3):384-94.

Au SCL | Volume 3; Issue 1 (2022) | JOAR-3(1)-028 | Short Communication 